\title{
PENENTUAN RUTE TERDEKAT LOKASI KLINIK BERSALIN DI KOTA SURAKARTA MENGGUNAKAN ALGORITMA FLOYD WARSHALL
}

\author{
Taratya Indra Pratiwi ${ }^{1)}$; Yustina Retno Wahyu Utami ${ }^{2}$; Sri Hariyati Fitriasih ${ }^{3)}$ \\ 1) Program Studi Sistem Informasi, STMIK Sinar Nusantara \\ 2) Program Studi Teknik Informatika, STMIK Sinar Nusantara \\ 3) Program Studi Manajemen Informatika, STMIK Sinar Nusantara \\ ${ }^{1)}$ taratyaindrapratiwi@gmail.com; ${ }^{2)}$ yustina_retno@sinus.ac.id; ${ }^{3)}$ fitri@sinus.ac.id
}

\begin{abstract}
Maternity clinics are an option for mothers who will give birth, in addition to locations that are more affordable than hospitals, the place is evenly spread so that their presence can be identified. Maternity Clinic was also chosen because some mothers feel anxious to give birth in a hospital environment, conditions that can slow contractions, make labor longer and interventions are more likely. So giving birth to a baby in a maternity clinic is an alternative that is widely chosen. But not all of them know the location of the nearest Maternity Clinic. Then you will find a way to help find the location of the Maternity Clinic in the city of Surakarta to be faster. The purpose of this study was to make it easier to find where the maternity clinic was located and be able to facilitate and provide access to the community who needed a search for a maternity clinic in the Surakarta area. This research proposes Floyd Warshall algorithm to provide the shortest route. The data used is clinic location data obtained from the Health Office. The results of this research are the shortest route that is connected in the Google Map, namely information on the location of Maternity Clinic locations and nodes scattered in the Surakarta area which can be of benefit to the community about Maternity Clinic places.

Keywords: Floyd Warshall Algorithm, Geographic Information System, Maternity Clinic, The Shortest Route
\end{abstract}

\section{PENDAHULUAN}

Angka kematian ibu (AKI) melahirkan dan angka kematian bayi (AKB) di Jawa Tengah masih tergolong cukup tinggi, termasuk di daerah Surakarta. Banyak terjadi kasus kematian ketika melahirkan dari tahun ke tahun yang mengalami peningkatan. Berdasarkan hal tersebut penulis mempunyai gagasan untuk membuat sistem informasi geografis pemetaan klinik bersalin yang mempunyai layanan sebagai salah satu sarana bagi Dinas Kesehatan khususnya, untuk mengetahui penyebaran fasilitas layanan bersalin di Kota Surakarta, dan bagi masyarakat dapat memperoleh informasi tentang penyebaran fasilitas layanan bersalin. Namun masyarakat khususnya pendatang yang belum mengetahui lokasi klinik bersalin yang ada di Kota Surakarta hal ini menjadi kendala, serta dengan wilayah yang luas, lalu lintas yang padat, banyaknya lampu lalu lintas dan banyaknya rute dapat menjadi kendala bagi yang belum hafal rute Kota Surakarta yang akan menimbulkan kebingungan untuk menentukan rute klinik bersalin karena gambaran tersebut tidak tersedia seperti visualisasi tempat, jarak antar daerah serta jalan yang akan dilalui.

Dari permasalahan diatas yang mendasari penulis membuat sistem informasi geografis pemetaan yang bertugas menyampaikan informasi klinik bersalin beserta rute terpendek yang diperuntukkan bagi para ibu yang dalam fase darurat akan melahirkan, sehingga diharapakan ibu-ibu dapat sampai ditujuan dengan efektif dan efisien. Sistem Informasi Geografis (SIG) merupakan sistem komputer yang memiliki empat kemampuan dalam menangani data yang bereferensi geografis: masukan, keluaran, manajemen data (penyimpanan dan pemanggilan data), analisis dan manipulasi data.

Tujuan penelitian untuk menentukan lokasi klinik bersalin dan rute terdekat klinik bersalin di wilayah Kota Surakarta dengan menggunakan metode Floyd Warshall sehingga waktu tempuh dapat dioptimalkan dan dapat mengetahui tempat klinik bersalin lain yang dilalui jalur tersebut. 


\section{TINJAUAN PUSTAKA}

\subsection{Sistem Informasi Geografis}

Sistem didefinisikan sebagai suatu tatanan (keterpaduan) yang terdiri atas sejumlah komponen fungsional (dengan satuan fungsi dan tugas khusus) yang saling berhubungan dan bersama - sama bertujuan untuk memenuhi proses tertentu[1]. Sedangkan informasi adalah sekumpulan fakta (data) yang diorganisasikan dengan cara tertentu sehingga mereka mempunyai arti bagi si penerima[2] sedangkan menurut Faisol[3], informasi adalah data yang telah diproses ke dalam suatu bentuk yang mempunyai arti bagi si penerima dan mempunyai nilai nyata dan terasa bagi keputusan saat itu atau keputusan mendatang.

Sistem Informasi Geografis merupakan sistem informasi yang digunakan untuk memasukkan, menyimpan, memanggil kembali, mengolah, menganalisa dan menghasilkan data geografis atau data geospatial untuk mendukung pengambilan keputusan dalam perencanaan dan pengelolaan penggunaan lahan, sumber daya alam, lingkungan transportasi, fasilitas kota dan pelayanan umum lainnya[4].

\subsection{Teori Dasar Graf}

Graf digunakan untuk merepresentasikan objek-objek diskrit dan hubungan antara objekobjek tersebut[4]. Sedangkan Elly[5] mengungkapkan bahwa, graf digunakan untuk merepresentasikan objek-objek diskrit dan hubungan antara objek-objek tersebut. Graf didefinisikan sebagai pasangan himpunan $(\mathrm{V}$, E) ditulis dengan notasi $\mathrm{G}=(\mathrm{V}, \mathrm{E})$ yang dalam hal ini $\mathrm{V}$ adalah himpunan tidak kosong dari simpul-simpul (vertices atau node) dan $\mathrm{E}$ adalah himpunan sisi (edges atau arcs) yang menghubungkan sepasang simpul. Menurut arah dan bobotnya, graf dibagi menjadi empat bagian yaitu:

1. Graf berarah dan berbobot adalah graf yang tiap verteks (titiknya) diwakili oleh sebuah anak panah yaitu sebuah kurva berarah dan setiap sisinya memiliki bobot.

2. Graf tidak berarah dan berbobot setiap sisi graf tidak terdapat anak panah atau sebuah kurva berarah. Disini urutan setiap simpulnya yang terhubung dari setiap vertex tidak diperhatikan.

3. Graf berarah dan tidak berbobot adalah graf yang setiap verteksnya diwakili sebuah anak panah yang menunjukkan sebuah arah, tapi setiap sisinya tidak memiliki bobot atau nilai.

4. Graf tidak berarah dan tidak berbobot adalah graf yang setiap vertex tidak diwakili sebuah anak panah dan setiap sisinya tidak memiliki bobot atau nilai.

\subsection{Algoritma Floyd Warshall}

Algoritma Floyd Warshall merupakan varian dari pemrograman dinamis, yaitu suatu mode yang melakukan pemecahan masalah dengan memandang solusi yang akan diperoleh sebagai suatu keputusan yang saling terkait. Algoritma diimplementasikan pada graf dengan menghitung bobot terkecil dari semua jalur yang menghubungkan sebuah pasangan titik, dan melakukannya sekaligus untuk semua pasangan titik[4].

Pada penelitian ini menggunakan algoritma Floyd Warshall metode maju dengan tujuan untuk mendapatkan solusi akhir dengan membangunnya dari tahap pertama hingga tahap terakhir-1. Tahapannya meliputi:

- tahap pertama (basis) tentunya dimulai dari node Awal.

$f_{1}(\mathrm{~s})=c x_{1} \mathrm{~s}$

- Selanjutnya bangun relasi rekurensinya. akan dinyatakan dengan huruf $\mathrm{k}$ dan status dengan huruf s. Maka relasinya menjadi:

$f_{\mathrm{k}}(\mathrm{s})=\min x_{k}\left\{c x_{k} \mathrm{~s}+f_{k-1}\left(x_{k}\right)\right\}, \quad \mathrm{k}=2,3,4$

\subsection{Google Maps API.}

Google Maps merupakan suatu peta yang dapat dilihat dengan menggunakan suatu browser. Dengan menggunakan Google Maps API, kita dapat menghemat waktu dan biaya untuk membangun aplikasi peta digital yang handal, sehingga kita dapat fokus hanya pada data yang ditampilkan[4].

\subsection{Penelitian Terkait}

Penelitian yang mengimplementasikan Algoritma Floyd Warshall dilakukan oleh Nazam[6]. Penelitian tersebut berisikan tentang pengembangan sistem geografis yang dapat memberikan informasi jarak antara satu daerah dengan daerah lain, memberikan alternatif jalan dari satu daerah ke daerah lain, memberi informasi seputar daerah yang diinginkan, dan menemukan lokasi daerah yang dicari.

Penelitian berikutnya dilakukan oleh $\mathrm{Ni}$ Ketut Dewi Ari Jayanti, tentang Teknologi SIG yang mengintegrasikan operasi pengolahan data berbasis database[7]. Pengolahan data geografi meliputi pengambilan data berdasarkan kebutuhan, analisis statistik dengan menggunakan visualisasi yang khas 
serta berbagai keuntungan yang mampu ditawarkan analisis geografis melalui peta.

Implementasi Floyd warshall untuk penentuan rute juga diterapkan pada rute wisata Kota Semarang [8] dan pengangkutan Sampah [9]. Penentuan rute wisata di Kota Semarang dimaksudkan untuk mengefisiensi waktu, jarak, dan biaya. Peta Kota Semarang ditransformasikan kedalam bentuk diagram grafik. Algoritma Floyd-Warshall diterapkan dalam perhitungan bobot path dari diagram grafik untuk mencari rute terpendek ke obyek wisata populer di Kota Semarang[8]. Demikian pula untuk rute pengangkutan sampah dari TPS ke TPA di Kabupaten Kubu Raya diperlukan efisiensi waktu. Hal ini berkaitan dengan jumlah intensitas sampah yang cukup tinggi[9].

\section{METODE PENELITIAN}

3.1 Jenis Data

a. Data primer

Data Primer yang digunakan berupa jarak perjalanan, rute perjalanan dan tempat klinik bersalin yang ada di Kota Surakarta.

\section{b. Data Sekunder}

Data Sekunder adalah data yang diperoleh dari buku yang mendukung penelitian. Data diperoleh dari media pustaka tentang teoriteori tentang objek-objek yang digunakan dalam pembuatan aplikasi tersebut. sehingga aplikasi ini dapat dijadikan suatu aplikasi dengan landasan teori yang benar. Data Sekunder berupa catatan, laporan maupun buku bacaan lain seperti peta Kota Surakarta.

\subsection{Metode Pengumpulan data}

a. Studi Literatur.

Studi literatur untuk mencari referensi yang berkaitan dengan cara kerja perhitungan Algoritma Floyd Warshall dalam penentuan jarak terpendek.

b. Wawancara

Tahap wawancara dilakukan dengan cara tanya jawab secara langsung dengan pihak Dinas Kesehatan Kota Surakarta untuk memperoleh informasi data klinik bersalin di Kota Surakarta.

\subsection{Metode Analisa Sistem}

a) Analisis Sistem

Menganalisa kasus rute terpendek dengan Algoritma Floyd Warshall mengenai penjabaran dari hubungan antar node yang diambil berdasarkan struktur jalan lokasi klinik bersalin kawasan Surakarta yang dijadikan sampel.

b) Perancangan Sistem

Pada tahap ini dirancang proses, database dan entitiy relationship sistem penentuan rute terpendek secara garis besar dengan memperlihatkan masukan, proses dan keluaran dari sistem yang akan dirancang untuk penentuan rute terpendek pencarian Klinik Bersalin di Kota Surakarta. Diagram konteks berisi admin, yang memuat data jarak antar simpang serta data lokasi titik simpang, yang kemudian diproses oleh Algoritma Floyd Warshall untuk mengkalkulasi jarak terpendek yang akan digunakan, lalu disalurkan ke User, yang mana memuat map tiap-tiap lokasi titik, data lokasi, jarak terpendek dari tiap-tiap lokasi, serta rute map. Sementara user dapat mengakses semua tersebut asalkan terlebih dahulu mengirim titik awal dan titik tujuan yang akan dicari

c) Implementasi Sistem

Hasil rancangan diimplementasikan dengan Google Map API untuk dapat menampilkan jalur terpendek berupa titik yang dilalui yang menghubungkan antar node dalam hasil rute ke lokasi klinik bersalin Kota Surakarta.

d) Pengujian Sistem

Pengujian sistem yang dilakukan meliputi pengujian fungsionalitas sistem dan validasi

\section{HASIL DAN PEMBAHASAN}

\subsection{Analisa Sistem}

Peta yang diperoleh ditransformasikan ke dalam bentuk graf serta diberi bobot sesuai jarak hasil pengukuran dari satu titik ke titik yang lain. Berikut adalah contoh graf dari Pasar Kabangan menuju Klinik Bersalin Barokah yang menjadi titik tujuan ditunjukkan pada Gambar 1.

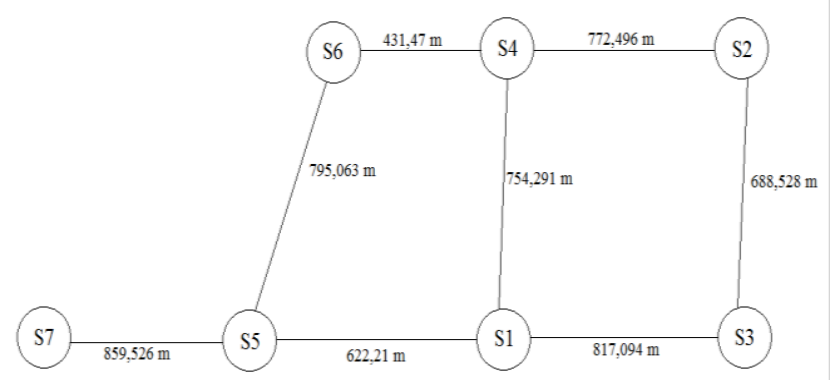

Gambar 1. Representasi Graf

Keterangan:

$$
\begin{array}{ll}
\text { S1 } & =\text { Pasar Kabangan (titik awal) } \\
\text { S2 } & =\text { Nonongan Slamet Riyadi } \\
\text { S3 } & =\text { Batik Keris } \\
\text { S4 } & =\text { Jackstar Cafe Slamet Riyadi }
\end{array}
$$




$$
\begin{array}{ll}
\text { S5 } & =\text { Pasar Jongke } \\
\text { S6 } & =\text { Perempatan Purwosari } \\
\text { S7 } & =\text { Klinik Bersalin Barokah (titik } \\
\text { akhir). } &
\end{array}
$$

Untuk mengetahui valid tidaknya, maka dilakukan perhitungan secara manual terlebih dahulu. Perhitungan manual menggunakan tabel yang terdiri dari beberapa tahap untuk mengetahui jarak terpendek dari Pasar Kabangan menuju Klinik Bersalin Barokah (1).

Pada tahap ini, akan dihitung berapa jarak dari titik awal (S1) menuju beberapa node terdekat berikutnya. Diketahui ada tiga node yang bisa dilewati dengan jalur yang berbeda pula, yaitu S5, S4, dan S3.

\section{Tabel 1. Tabel Perhitungan tahap 1}

\begin{tabular}{|c|c|c|}
\hline \multirow{2}{*}{$\mathrm{S}$} & \multicolumn{2}{|c|}{ Solusi Optimum } \\
\cline { 2 - 3 } & $f_{1}$ & $x_{1}$ \\
\hline S5 & 622,21 & $\mathrm{~S} 1$ \\
\hline S4 & 754,291 & $\mathrm{~S} 1$ \\
\hline S3 & 817,094 & $\mathrm{~S} 1$ \\
\hline
\end{tabular}

\section{Tahap 2:}

Perhitungan di tahap dua ini menggunakan Rumus (2), yakni dengan menambahkan nilai dari hasil perhitungan Tabel 1 ke titik-titik berikutnya. Masing-masing jarak S5, S4, dan S3 akan ditambahkan dengan node yang berada pada titik selanjutnya, yaitu S7, S6, dan S2. Karena berdasarkan keterangan graf Klinik Bersalin Barokah berada pada S7, maka langsung diketahui berapa hasil jarak menuju titik tujuan.

\begin{tabular}{|c|c|c|c|c|c|}
\hline \multirow[t]{2}{*}{$x_{2} \mathrm{~S}$} & \multicolumn{3}{|c|}{$f_{2}\left(x_{2}, s\right)=c x_{2} s+f_{1}\left(x_{2}\right)$} & \multicolumn{2}{|c|}{ Solusi Optimum } \\
\hline & S5 & S4 & S3 & $f_{2}(\mathrm{~s})$ & $x_{2}$ \\
\hline S7 & 1481,7359 & $\infty$ & $\infty$ & 1481,7959 & S5 \\
\hline S6 & 1417,273 & 1185,761 & $\infty$ & 1185,761 & S4 \\
\hline S2 & $\infty$ & 1526,787 & 1505,622 & 1505,622 & S3 \\
\hline
\end{tabular}
Hasil perhitungan tahap 2 dapat kita lihat seperti pada Tabel 2 berikut.

Tabel 2. Tabel perhitungan tahap 2

Berdasarkan perhitungan tersebut, diketahui bahwa hasil dari S6 dan S3 masih harus melewati beberapa titik untuk menuju S7.

\subsection{Perancangan Sistem}

\section{Data Flow Diagram (DFD)}

Perancangan untuk sistem penentuan rute terpendek ke klinik bersalin di sajikan pada Gambar 2.

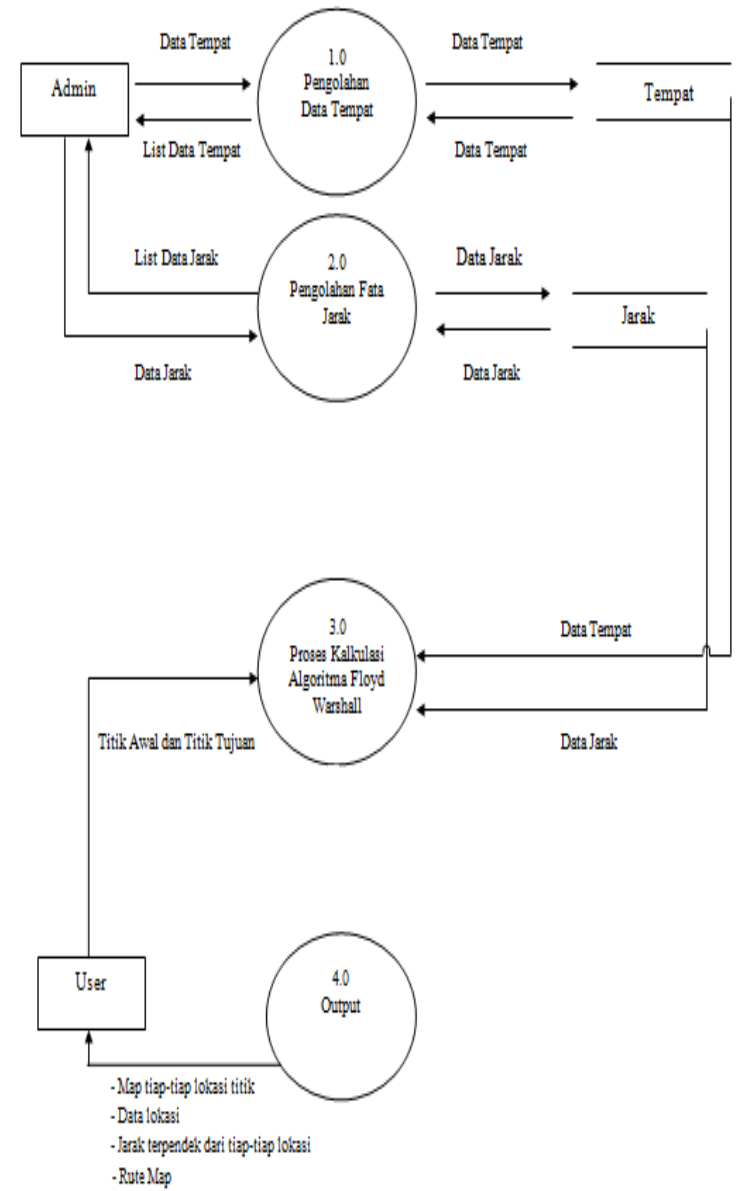

Gambar 2. DFD Level 0

\section{Entity Relationship Diagram (ERD)}

Gambar 3 berikut adalah ERD yang terdiri terdiri dari entitas, atribut, dan relasi.

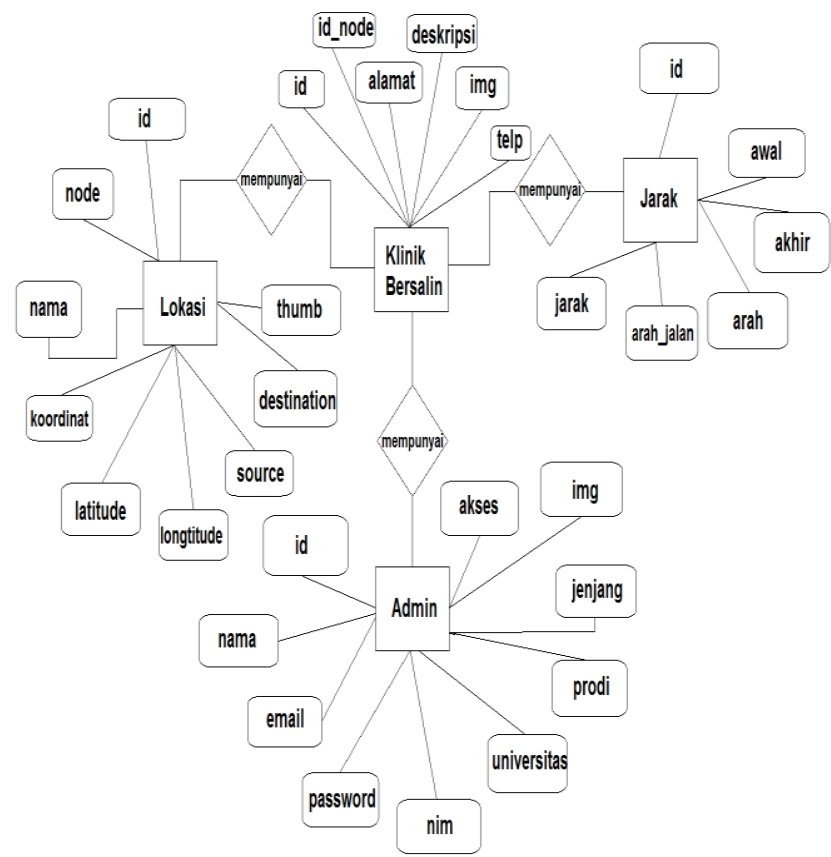

Gambar 3. ERD Rute Terpendek ke Klinik Bersalin 


\subsection{Implementasi}

\section{a. Fungsi Floyd Warshall}

Pseuducode algoritma Floyd Warshall yang digunakan untuk pencarian rute terpendek ditunjukkan pada Gambar 4.

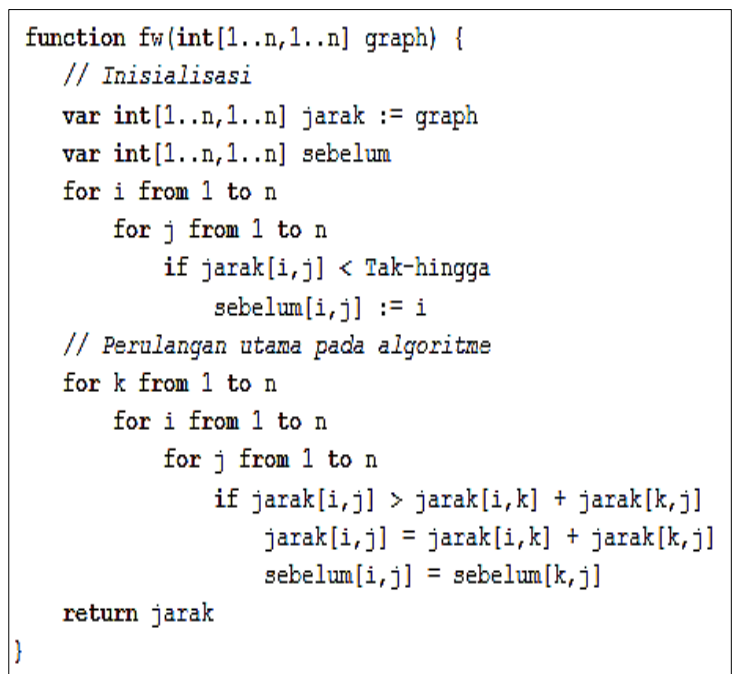

\section{Gambar 4. Formula Floyd Warshall}

Berdasarkan Gambar 4, jarak terpendek dihasilkan dari rekurens menggunakan nested for yang mana pasangan titik dilambangkan dengan indeks baris dan kolom.

\section{b. Alur Algoritma Floyd Warshall}

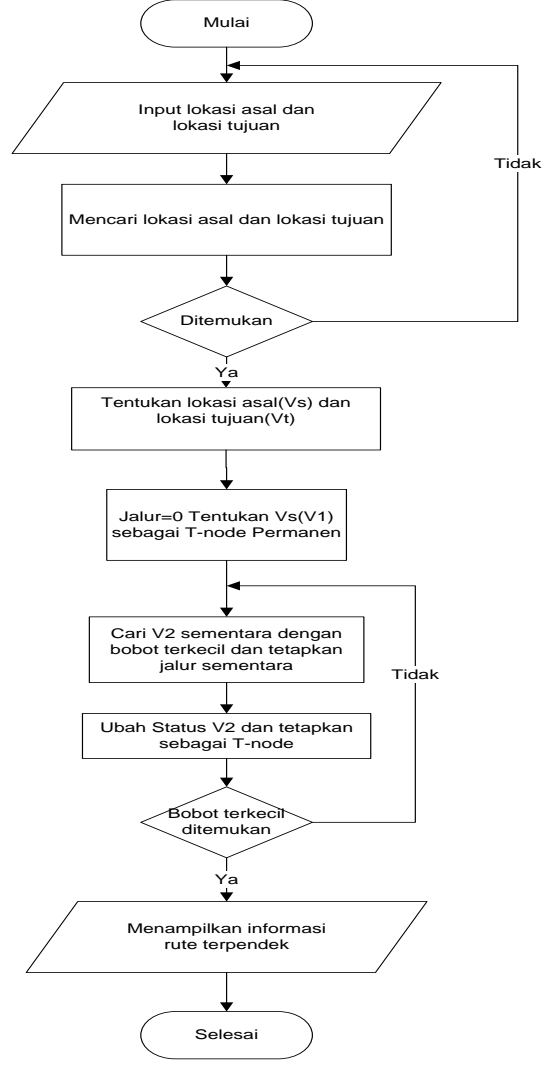

Gambar 5. Formula Floyd Warshall

\section{c. Implementasi Rute}

Pada pengujian ini, akan ditentukan rute terpendek yang akan dipilih algoritma Floyd warshall. User memilih titik awal pada bagian Lokasi Awal, maka tempat-tempat yang menjadi titik utama akan ditampilkan. Setelah itu memilih tempat Klinik Bersalin yang akan dituju, maka nama tempat Klinik Bersalin akan muncul.

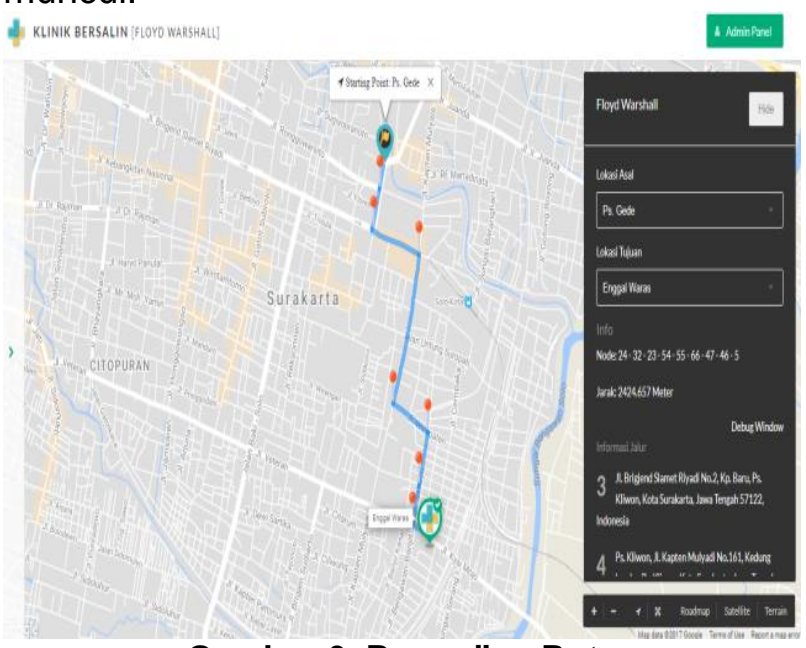

\section{Gambar 6. Pengujian Rute}

\section{d. Implementasi Informasi Lokasi}

Pada pengujian Informasi Lokasi, akan ditunjukkan informasi-informasi Klinik Bersalin yang tercantum. User mengeklik panah kecil yang ada disebelah kiri web, maka ada form yang menggeser otomatis yang menunjukkan data dari Klinik Bersalin yang ada.

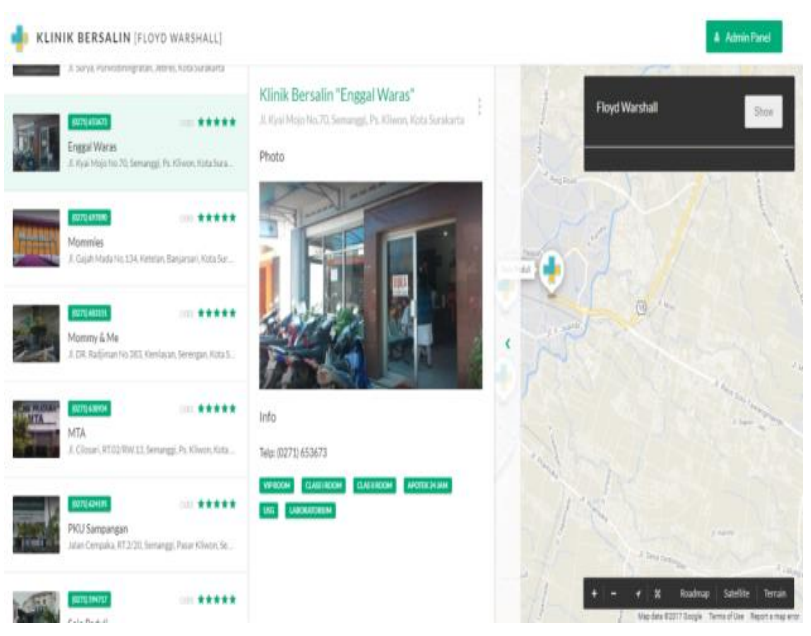

Gambar 7. Pengujian Informasi Lokasi

\section{e. Implementasi Data}

Bagian Pengujian Data bisa diakses setelah melakukan aktivitas Login. Bila data sesuai, maka tampilan khusus admin akan muncul. Bagian ini merupakan satu tingkat lebih dalam daripada yang biasa diakses oleh user yang bukan admin, karena memuat 
tampilan yang berisi informasi semua node yang dibuat, jalur-jalurnya pun akan terlihat bersambungan satu sama lain, tidak seperti pada tampilan tanpa login yang rutenya hanya muncul satu garis karena yang diutamakan adalah menampilkan lokasi terdekat.

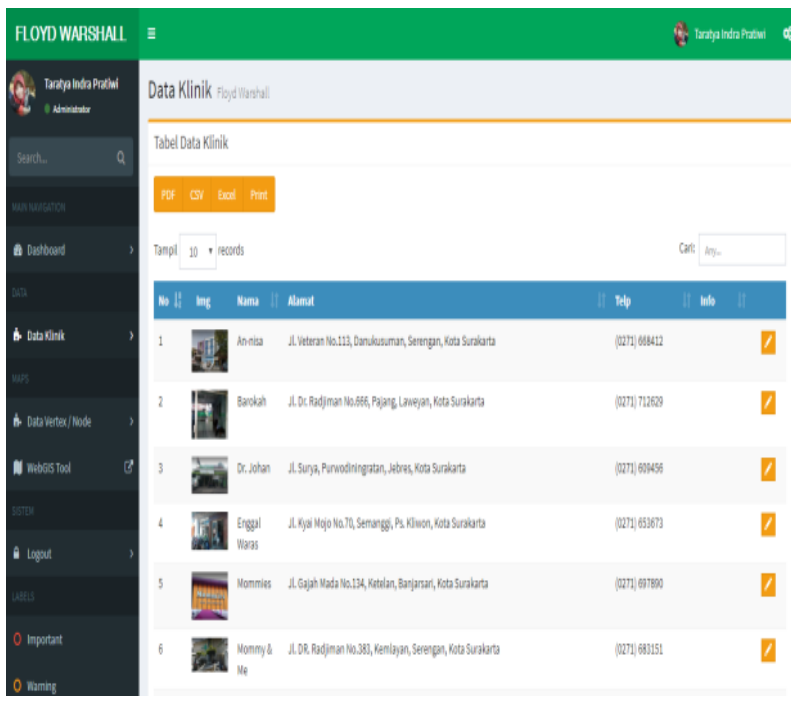

Gambar 8. Pengujian Data

\subsection{Pengujian Sistem}

\section{a. Pengujian Fungsional}

Pengujian fungsional merupakan teknik pengujian yang digunakan untuk menguji fitur atau fungsi dari sistem perangkat lunak, harus mencakup semua skenario dan kesimpulan.Berikut adalah hasil dari pengujian Fungsional.

Tabel 3 Tabel Pengujian Fungsional

\begin{tabular}{|c|c|c|c|}
\hline $\begin{array}{l}\text { Komponen } \\
\text { yang Diuji }\end{array}$ & $\begin{array}{l}\text { Skenario } \\
\text { Pengujian }\end{array}$ & Pengamatan & $\begin{array}{c}\text { Kesim- } \\
\text { pulan }\end{array}$ \\
\hline $\begin{array}{c}\text { Pengujian } \\
\text { Rute }\end{array}$ & $\begin{array}{l}\text { Menampilkan } \\
\text { hasil rute } \\
\text { terpendek yang } \\
\text { ditampilkan } \\
\text { dalam bentuk } \\
\text { variabel sesuai } \\
\text { dengan titik-titik } \\
\text { yang muncul } \\
\text { pada peta. }\end{array}$ & $\begin{array}{l}\text { Data didapat } \\
\text { dengan } \\
\text { mengeklik lokasi } \\
\text { awal, lalu lokasi } \\
\text { tujuan. Hasil } \\
\text { menunjukkan } \\
\text { jalur terdekat } \\
\text { dapat } \\
\text { ditampilkan. }\end{array}$ & Sesuai \\
\hline $\begin{array}{c}\text { Pengujian } \\
\text { Informasi } \\
\text { Lokasi }\end{array}$ & $\begin{array}{l}\text { Menampilkan } \\
\text { data dari klinik } \\
\text { bersalin yang } \\
\text { tercantum. }\end{array}$ & $\begin{array}{l}\text { Hasil yang } \\
\text { ditampilkan } \\
\text { adalah } \\
\text { informasi- } \\
\text { informasi dari } \\
\text { klinik bersalin, } \\
\text { diantaranya foto, } \\
\text { alamat lokasi, } \\
\text { serta nomor } \\
\text { telepon }\end{array}$ & Sesuai \\
\hline $\begin{array}{l}\text { Pengujian } \\
\text { Login }\end{array}$ & $\begin{array}{l}\text { Memasukkan } \\
\text { username dan } \\
\text { password } \\
\text { untuk login ke } \\
\text { admin. } \\
\text { Jika data } \\
\text { sesuai, maka } \\
\text { dianggap } \\
\text { benar. }\end{array}$ & $\begin{array}{l}\text { Data login } \\
\text { dimasukkan dan } \\
\text { ketika valid, } \\
\text { maka akan } \\
\text { masuk ke menu } \\
\text { utama admin. }\end{array}$ & Sesuai \\
\hline
\end{tabular}

\begin{tabular}{|c|l|l|c|}
\hline $\begin{array}{c}\text { Komponen } \\
\text { yang Diuji }\end{array}$ & \multicolumn{1}{|c|}{$\begin{array}{c}\text { Skenario } \\
\text { Pengujian }\end{array}$} & \multicolumn{1}{|c|}{ Pengamatan } & $\begin{array}{c}\text { Kesim- } \\
\text { pulan }\end{array}$ \\
\hline & $\begin{array}{l}\text { Memasukkan } \\
\text { username dan } \\
\text { password } \\
\text { untuk login ke } \\
\text { admin. } \\
\text { Jika data tidak } \\
\text { sesuai, maka } \\
\text { dianggap }\end{array}$ & $\begin{array}{l}\text { Data login } \\
\text { dimasukkan dan } \\
\text { jika informasi } \\
\text { yang diinput } \\
\text { tidak valid, maka } \\
\text { muncul info } \\
\text { kesalahan. }\end{array}$ & Sesuai \\
\hline $\begin{array}{c}\text { Pengujian } \\
\text { Data }\end{array}$ & $\begin{array}{l}\text { Merubah } \\
\text { informasi data } \\
\text { klinik bersalin } \\
\text { pada halaman } \\
\text { admin. }\end{array}$ & $\begin{array}{l}\text { Data klinik } \\
\text { bersalin dapat } \\
\text { diperbaharui } \\
\text { informasinya, } \\
\text { seperti merubah } \\
\text { foto lokasi dan } \\
\text { mengganti } \\
\text { alamat. }\end{array}$ & Sesuai \\
& & \\
& &
\end{tabular}

\section{b. Pengujian Validitas}

Pengujian Validitas digunakan untuk mengetahui apakah hasil dari aplikasi program menunjukkan kesesuaian atau tidak dengan hasil perhitungan manual. Gambar 9 adalah hasil perhitungan program.

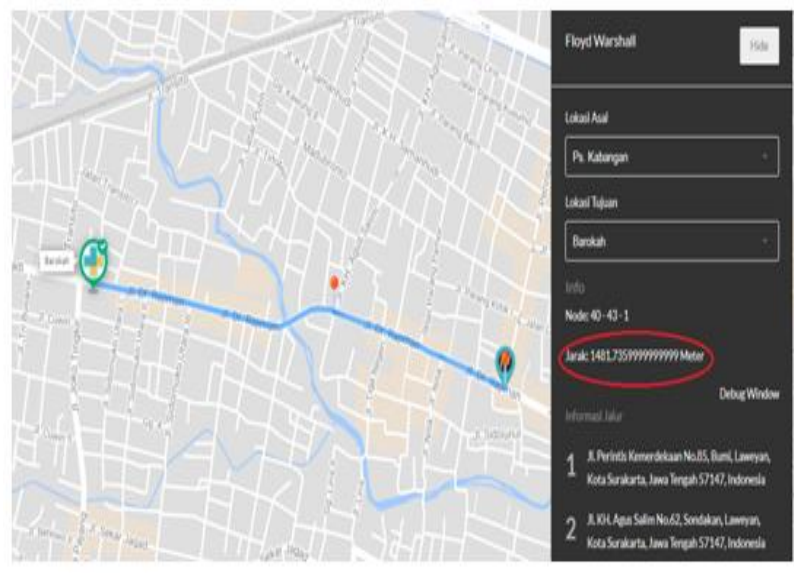

Gambar 9. Hasil Perhitungan Program

Selanjutnya, akan dilakukan perbandingan dengan hasil perhitungan manual. Hasil perbandingannya disajikan pada Tabel 4.

Tabel 4 Tabel Perbandingan Hasil

\begin{tabular}{|l|l|l|l|l|l|}
\hline \multirow{3}{*}{ Rute } & \multicolumn{2}{|c|}{ Manual } & \multicolumn{2}{c|}{ Program } & \multirow{2}{*}{ Hasil } \\
\cline { 2 - 5 } & $\begin{array}{c}\text { Rute } \\
\text { Alternatif }\end{array}$ & $\begin{array}{c}\text { Jarak } \\
(\mathrm{m})\end{array}$ & \multicolumn{1}{|c|}{ Rute } & $\begin{array}{c}\text { Jarak } \\
(\mathrm{m})\end{array}$ & \\
\hline S1-S7 & S1-S4- & 2840,35 & S1-S5- & $\mathbf{1 4 8 1 , 7}$ & VALID \\
& S6-S5- & & S7 & $\mathbf{3 5 9 9 9}$ & \\
& S7 & & & & \\
\cline { 2 - 3 } & S1-S3- & 4364,17 & & & \\
& S2-S4- & 7 & & & \\
& S6-S5- & & & & \\
& S7 & & & & \\
\cline { 2 - 3 } & S1-S5- & $\mathbf{1 4 8 1 , 7 3}$ & & & \\
& S7 & $\mathbf{5 9 9 9}$ & & & \\
\hline
\end{tabular}




\section{PENUTUP}

\subsection{Kesimpulan}

Berdasarkan analisis dan implementasi sistem penentuan rute terpendek Klinik Bersalin yang dilakukan oleh peneliti, maka dapat diambil beberapa kesimpulan, yaitu:

1. Algoritma Floyd Warshall dapat diimplementasikan untuk penentuan rute terpendek menuju Klinik Bersalin berbasis sistem informasi Geografis.

2. Berdasarkan pengujian fungsionalitas menggunakan metode black box, aplikasi yang dikembangkan telah sesuai dengan skenario yang diujikan.

\subsection{Saran}

Aplikasi penentuan rute terpendek untuk Klinik Bersalin yang dikembangkan, masih didasarkan pada kriteria jarak saja dan berbasis web, oleh karena itu disarankan beberapa hal sebagai berikut:

1. Sistem dapat dikembangkan dengan menambahkan kriteria waktu tempuh dan kepadatan untuk mencari rute terpendek.

2. Sistem dapat dikembangkan untuk aplikasi yang bersifat mobile agar mudah diakses oleh pengguna.

\section{DAFTAR PUSTAKA}

[1] Yakub, Pengantar Sistem Informasi. Yogyakarta: Graha IImu, 2013.

[2] S. Adam, Penggunaan Quantum GIS Dalam Sistem Informasi Geografis. Bogor: Andi, 2012.

[3] A. Faisol and Indarto, Tutorial Ringkas ArcGIS -10. Yogyakarta: Andi, 2013.

[4] Riyanto, P. E. Putra, and H. Indelarko, Tuntunan Praktis: Pengembangan Aplikasi Sistem Informasi Geografis Berbasis Desktop dan Web. Yogyakarta: Gava Media, 2009.

[5] M. J. Elly, Sistem Informasi Geografis. Yogyakarta: Graha IImu, 2009.

[6] A. Nazam, Penentuan Rute Terpendek Untuk Distribusi Paket Pos Menggunakan Algoritma Floyd Warshall. Yogyakarta: Tesis, Program Pasca Sarjana IImu Komputer, STMIK AKAKOM, 2014.

[7] N. K. D. A. Jayanti, Penggunaan Algoritma Floyd Warshall Dalam Masalah Jalur Terpendek Pada Penentuan Tata Letak Parkir. Surabaya: Tesis, Program Pasca Sarjana IImu Komputer, STMIK STIKOM, 2014.

[8] F. W. Ningrum and T. Andrasto, "Penerapan Algoritma Floyd-Warshall dalam Menentukan Rute Terpendek pada Pemodelan Jaringan Pariwisata di Kota Semarang," J. Tek. Elektro, vol. 8, no. 1, pp. 21-24, 2016.

[9] V. Setiawan, M. Kiftiah, and W. B. Partiwi, "Lintasan Terpendek Pengangkutan Sampah ( Studi Kasus: Pengangkutan Sampah di Kabupaten Kubu Raya )," Bul. IIm. Math. Stat. dan Ter., vol. 6, no. 3, pp. 221-230, 2017. 